\title{
Analysis of Factors Affecting Grain Output in China
}

\author{
Zhizhi Chen ${ }^{1, \text { a }}$, Shan $\mathrm{Gao}^{2, \mathrm{~b}}$, and Linze $\mathrm{Li}^{3, \mathrm{c}}$ \\ ${ }^{1}$ School of Statistics, Jilin University of Finance and Economics, Changchun, Jilin Province, P.R. China, \\ 130117 \\ ${ }^{2}$ School of Statistics, Jilin University of Finance and Economics, Changchun, Jilin Province, P.R. China, \\ 130117 \\ ${ }^{3}$ School of Statistics, Jilin University of Finance and Economics, Changchun, Jilin Province, P.R. China, \\ 130117 \\ achenzz2009@126.com, b806088831@qq.com, 1904191509@qq.com
}

Keywords: Production function of Cobb Douglas, Total grain yield, Econometric analysis

\begin{abstract}
The total grain yield has significant influence on the development of national economy, international politics, social security and so on. As the cornerstone of national stability, it is of great strategic significance to study the influencing factors of total grain yield. The total power of agricultural machinery, the amount of fertilizer applied and the disaster area of crops are the independent variables affecting the total grain yield, and the total grain yield is regarded as the dependent variable. The data are analyzed by Eviews software. Taking the improved Cobb-Douglas production function as the model, the econometric analysis is carried out. The main factors influencing the total grain yield are given. We should have the conclusion of cultivated land irrigation area and the total power of agricultural machinery, put forward some suggestions, such as protecting cultivated land resources, stabilizing grain planting area, promoting agricultural scientific and technological innovation, setting up agricultural lecture hall, increasing the level of agricultural mechanization, liberating labor force, and so on.
\end{abstract}

\section{Introduction}

By 2017, China's population has reached 1.405 billion, accounting for $18.11 \%$ of the world's population. China is the world's largest country with a population of 9.601 million square kilometers, accounting for $7.2 \%$ of the world's land area. What is more noteworthy is that the cultivated area is only 1.543 million square kilometers, which can be said to be nurtured with $7 \%$ of the land. Eighteen percent of the world's population, China's agricultural pressure is very huge. Although in recent years, China's population growth rate has slowed down, but on the whole still maintains a growth trend, the natural growth rate of population in 2016 is 5.86\%. In addition, China opened the "two-child policy" in 2016, the population growth trend is bound to accelerate, agricultural food pressure is bound to increase. In addition, with the rapid development of urbanization in China, the increasing area of urbanization has squeezed the cultivated area. Moreover, some areas are mostly mountainous areas, basins, deserts and other areas, which are not suitable for cultivating wheat, rice, corn and other food crops. This will also lead to the shortage of land resources. In addition, natural disasters are also an important factor, drought and flood disasters are more frequent in China, debris flow disasters often occur in the Pearl River Delta region, some coastal cities are also plagued by tornadoes, statistics show that in 2016, the number of sudden environmental conditions reached 304 times. All these objective conditions have led to the lack of strategic grain supply in China.

In order to explore ways to increase the total grain output, it is necessary to start with its influencing factors, analyze the relationship between the various influencing factors and grain output, so as to formulate corresponding policies and measures to improve grain production technology and improve grain productivity. Agriculture, as a department depending on natural environment, is greatly influenced by many natural factors such as soil fertility, rainfall and 
sunshine time. In this paper, the factors which are relatively universal and stable and controllable are selected from many uncontrollable factors to analyze, aiming at evaluating each factor. The impact of dependent variables and the possible future development of the forecast, so as to enhance the implementation of the recommendations, with a more clear purpose, and help the state to formulate a scientific and effective food production plan, to provide a reliable basis for relevant policies.

\section{Methodology}

\subsection{Analysis of factors affecting grain production and model establishment}

The total yield of grain, irrigation area of cultivated land, total power of agricultural machinery, fertilizer application and disaster area of crops were selected to analyze. The total grain yield includes wheat, rice, corn, sorghum and other major crop yields, in this paper as a dependent variable $y$.The others are independent variable which are denoted in order as $x_{1}, x_{2}, x_{3}, x_{4}$. We collected data from 1986 to 2016 for analysis.

The basic form of Cobb Douglas production function is: $y=A t L^{\alpha} K^{\beta} \mu$. The new production function is: $y=C x_{1}^{\alpha_{1}} x_{2}^{\alpha_{2}} x_{3}^{\alpha_{3}} x_{4}^{\alpha_{4}}$. The variables are logarithmic so as to better explain the relationship between variables and transform them into multiple linear equations.

$$
\ln \mathrm{y}=c+\alpha_{1} \ln \mathrm{x}_{1}+\alpha_{2} \ln \mathrm{x}_{2}+\alpha_{3} \ln \mathrm{x}_{3}+\alpha_{4} \ln \mathrm{x}_{4}
$$

\subsection{An empirical analysis of grain output in China}

The ADF test was used to analyze the stationarity of the data. It can be seen from the test results that all variables are stationary time series after differential, and regression analysis can be carried out by means of ADF test. The fitting equation of the model obtained by least square method is

$$
\begin{aligned}
\nabla \ln \mathrm{y}= & 0.090134+1.329034 \nabla \ln \mathrm{x}_{1}-0.047406 \nabla \ln \mathrm{x}_{2} \\
& +0.011613 \ln \mathrm{x}_{3}+0.098614 \nabla \ln \mathrm{x}_{4}
\end{aligned}
$$

It can be seen from the results that $R^{2}=0.613373$ and adjusted $R^{2}=0.553892$. The results showed that the overall linear relationship between the total grain yield and the independent variables was not strong, but it was positively correlated, and the fitting effect of the model was not good. The equation is not significant. Except $\nabla \ln x_{1}$ and $\nabla \ln x_{4}$, none of the other variables passed parametric significance test. It is considered that there exist multiple collinearity between independent variables. After the correction of multiple collinearity by stepwise regression method, we can get the total production function of grain in China:

$$
\nabla \ln \mathrm{y}=1.072959 \nabla \ln \mathrm{x}_{1}+0.101527 \nabla \ln \mathrm{x}_{4}
$$

After testing, there is no heteroscedasticity and autocorrelation in the model.

\section{Conclusions and recommendations}

\subsection{Conclusions}

By establishing the improved Cobb Douglas production function model, the ADF unit root test and model fitting were carried out on the data. The final grain yield model in China showed that the contribution of fertilizer use and disaster area to grain yield was not significant enough. Therefore, the two independent variables were eliminated and the factors affecting grain yield were analyzed. There are mainly farmland irrigation area and total power of agricultural machinery, both of which have a positive impact on total grain output. Under the assumption that the remaining conditions remain unchanged, if the difference of cultivated land irrigated area increases by $1 \%$, the difference of total grain output increases by $1.072959 \%$ on average, indicating that agricultural land use area is 
one of the direct factors affecting grain output; if the difference of total power of agricultural machinery increases by $1 \%$, the difference of total grain output will be very significant. The average increase of value was $0.101527 \%$, indicating that the total power of agricultural machinery has a strong impetus to grain production in China. Land, labor force and investment capital are the three indispensable factors in agricultural production. Under the condition of fixed cultivated land area, the transformation from traditional agriculture to modern agriculture is the process of increasing the total power of agricultural machinery, which is effectively reduced by installing more mechanical seeding, mechanical irrigation and mechanical harvesting equipment. The dependence of agricultural production on artificial labor force liberates human labor force from traditional agriculture. The total power of agricultural machinery has a positive impact on grain output. The state can increase the total grain output by improving the level of agricultural machinery and vigorously developing agricultural science and technology.

In this paper, the method of choosing explanatory variables is not perfect. There is no asset investment in the input of grain production factors, because land leasing and the input of agricultural machinery accounted for a large proportion in the investment of agricultural assets. Therefore, capital investment has not been introduced. This paper mainly cites land factors and technical factors, but because the selected indicators are relatively single, can not fully explain the factors affecting China's total grain output, which is the shortcomings of this paper

\subsection{Recommendations}

Earnestly protect cultivated land resources and stabilize grain growing area. China is the world's most populous country, but the land occupied is very scarce, so we must emphasize the protection of cultivated land area, also prevent the occupation of grain cultivation and irrigation area by the real estate industry. At the same time, we need to improve the efficiency of land use, optimize the land structure and establish a good farmland management. Rationale system, so that land resources to obtain a reasonable allocation of resources. If we can ensure the rational use of land resources, we can guarantee the area of cultivated land, and then stabilize the output of grain. At the same time, the optimization of land structure will improve the quality of land, maintain the sustainable development, and realize the dynamic balance of cultivated land. In this case, the quantity and quality of grain will be very large. Improve. In this regard, the government should first establish people's awareness of the protection of cultivated land resources, on the one hand, to expand publicity to strengthen people's sense of responsibility for land, so that people consciously protect land, and actively take effective measures to avoid the situation of soil erosion. On the one hand, we should formulate relevant policies and regulations, strictly implement the accountability system, improve land management methods, and ensure that agricultural farmland is not converted into non-agricultural land. At the critical moment when the situation of total grain production is grim and the pressure of protecting the effective planting area of land is enormous, the protection of land is the primary measure to ensure social security.

Promote agricultural science and technology innovation and set up agricultural lecture hall. Although agricultural work is not confined to the countryside, the rural population is still the main force of agricultural work. At present, the rural population structure is mainly composed of the elderly, women and children. Most of the young and male labor force work outside, resulting in low rural labor force and low quality of workers. It is precisely for this reason that agricultural technology lags behind, which to a great extent affects the yield of grain. To solve this problem, we can start from two aspects. First, the government can provide technical support in some areas with low agricultural labor force. Subsidies should be given to farmers in purchasing seeds and fertilizers to enable them to purchase high-quality seeds and to set up lectures to improve their scientific and cultural qualities. Farmers, as the first-line agricultural practitioners, their knowledge of agricultural science and technology will be directly related to grain production. They will explain how to use chemical fertilizers reasonably and effectively, how to deal with drought and flood disasters and so on, in order to achieve the goal of increasing total grain production. Second, the government should increase investment in agricultural research. According to the China Statistical Yearbook, the 
government's investment in agricultural scientific research accounts for only $1 \%$ of the total investment, which is far behind the average level of $2.5 \%$ in developed countries. This shows that the government has not paid enough attention to the problem of grain production in China, which is also an important reason for the decline of grain production. Therefore, we should establish a stable investment mechanism for agricultural scientific research to improve agricultural technology level, through the integration and optimization of scientific and technological resources, so that the development of agriculture and other sectors of the national economy to achieve a consistent pace.

Increase the level of agricultural mechanization and liberate labor force. In recent years, with the rapid development of science and technology in China, agricultural machinery has been widely used, but it has only replaced $46 \%$ of the country's agricultural labor force. In many backward areas, it still relies on human labor. Therefore, the government can provide preferential policies for agricultural machinery to help farmers improve labor efficiency in harvesting, irrigation and planting. The realization of agricultural machinery production process automation, operation information. In addition, China's production conditions, agricultural management, agricultural infrastructure need to be improved, but also continue to build the road of agricultural transformation.

\section{Acknowledgements}

Educational reform project of Jilin Provincial Department of Education, Soft science project of Jilin science and Technology Department [20170418068FG].

\section{References}

[1] Ramanathan, R. Introductory Econometrics with Applications, 4th ed. [M]. The Dryden Press, 1998.

[2] Z.N. Li, W.Q. Pan, Econometrics.4 ${ }^{\text {th }}$. ed. [M]. Beijing: Higher Education Press, 2017.1. (In Chinese).

[3] Mária Babulicová, Lubomír Mendel. The Grain Yield and Weed Infestation Rate of Winter Wheat by the Different Share of Cereals in Crop Rotations [J]. Agriculture, 2011, 57(1):11-13.

[4] G.M. Wang, Q.Y. Zhou. An empirical analysis of factors affecting China's comprehensive grain production capacity [J]. Journal of Sichuan University (Philosophy and Social Sciences). 2016(3):82-88. (In Chinese).

[5] F.D. Li. Analysis of main factors affecting grain yield in Xinjiang [J]. China Agricultural Machinery Chemical Report. 2016,37(5):268-274. (In Chinese).

[6] J.P. Jiao. Study on the improvement of comprehensive grain production capacity in Sanjiang plain of Heilongjiang Province [J]. Journal of Anhui Agricultural Sciences. 2017,45(23):222-224. (In Chinese).

[7] Piotr Kraska, Edward Pałys. Grain yielding and chemical composition of winter triticale cultivated in monoculture in conditions of different doses herbicides[J]. Annals UMCS, Agricultura, 2008, 63(2): 22-25. 